\title{
Impact of scaffolding protein TNRC6 paralogs on gene expression
}

\author{
and splicing
}

Samantha T. Johnson, Yongjun Chu', Jing Liu, and David R. Corey ${ }^{*}$

UT Southwestern Medical Center, Departments of Pharmacology and Biochemistry, Dallas, TX 75205, ${ }^{1}$ current address, Exact Sciences, 445 N. $5^{\text {th }}$ Street, Phoenix, AZ85004

${ }^{*}$ To whom correspondence should be addressed

Running Head Title: Impact of TNRC6 on gene expression and splicing

Keywords: RNA interference, TNRC6, GW182, alternative splicing, Argonaute, RNA sequencing 


\section{ABSTRACT}

TNRC6 is a scaffolding protein that bridges interactions between small RNAs, argonaute (AGO) protein, and effector proteins to control gene expression. There are three paralogs in mammalian cells, TNRC6A, TNRC6B, and TNRC6C. These paralogs have $\sim 40 \%$ amino acid sequence identity and the extent of their unique or redundant functions is unclear. Here, we use knockout cell lines, enhanced crosslinking immunoprecipitation (eCLIP), and high-throughput RNA sequencing (RNAseq) to explore the roles of TNRC6 paralogs in RNA-mediated control of gene expression. We find that that the paralogs are largely functionally redundant and changes in levels of gene expression are well-correlated with those observed in AGO knockout cell lines. Splicing changes observed in AGO knockout cell lines are observed in TNRC6 knockout cells. These data further define the roles of the TNRC6 isoforms as part of the RNA interference (RNAi) machinery. 


\section{INTRODUCTION}

Scaffolding proteins play critical roles in biology by bringing proteins with diverse functions into proximity (Shaw and Filbert 2009). Their ability to guide the formation of complexes increases the effective concentrations of proteins and nucleic acids relative to one another, allowing for more efficient activities inside cells. One important example of scaffolding proteins is the GW182 family (Eystathioy et al. 2002) which plays a critical role facilitating the regulation of gene expression during RNA interference (RNAi) (Baillat and Shiekhattar 2009; Takimoto et al. 2009; Niaz and Hussain 2018).

In vertebrates, there are three GW182 protein paralogs, also known as trinucleotide repeat containing protein 6A (TNRC6A), TNRC6B, and TNRC6C. These are multidomain proteins consisting of an argonaute (AGO) binding domain that can bind up to three AGO protein paralogs (Nishi et al. 2013; Pfaff et al. 2013; Elkayam et al. 2017), CCR4-NOT interacting motif (CIM) (Chekulaeva et al. 2011; Fabian et al. 2011), an ubiquitin associated-like (UBL) domain (Nishi et al. 2013), a glutamine rich domain (Q-rich) (Baillat and Shiekhattar 2009), a PABP-interacting motif 2 (PAM2) (Fabian et al. 2009; Lazzaretti et al. 2009), and an RNA recognition motif (RRM) (Eulalio et al. 2009) (Figure 1A).

For RNA interference, TNRC6 plays a critical bridging role. AGO protein binds miRNA guide strands and the miRNA:AGO complex associates with complementary target RNA sequences. TNRC6 binds to AGO through the one of two (in TNRC6B) or three (TNRC6A or TNRC6C) motifs in the AGO binding domain (Elkayam et al. 2017)

(Figure 1A). The ability of TNRC6 to bind multiple AGO proteins permits enhanced association through cooperative binding between two or three AGO:miRNA complexes 
(Broderick et al. 2011; Gebert and MacRae 2019; Briskin et al. 2020). Mass spectrometry has identified other accessory proteins binding to TNRC6 domains that may contribute to the control of gene expression (Hicks et al. 2017; Suzawa et al. 2017; Sarshad et al. 2018). The best known TNRC6 interactor is the CCR4-NOT complex that is responsible for translation repression during RNAi (Behm-Ansmant et al. 2006; Fabian et al. 2011; Collart 2016) but was initially discovered as a regulator of gene transcription (Albert et al. 2000).

This partnership between AGO and TNRC6 proteins is central to understanding how RNAi governs gene expression. Here, we use TNRC6 knockout and knockdown cells deficient in $T N R C 6 A, T N R C 6 B$, and $T N R C 6 C$ expression in combination with enhanced crosslinking immunoprecipitation (eCLIP) (van Nostrand et al, 2016) and RNA sequencing (RNAseq) to investigate the potential for unique and redundant function for the TNRC6 paralogs during RNAi. We find that the TNRC6 paralogs are largely redundant and that effects on gene expression are remarkably consistent to those observed when AGO proteins are knocked out.

\section{RESULTS}

\section{Experimental Design: TNRC6 knockout and knockdown cells}

We have previously described TNRC6 A-/-, TNRC6 B-/-, and TNRC6 AB-/- knockout cell lines (Liu et al. 2019). HCT116 colorectal cancer cells were chosen as a parental line because they are diploid, which facilitates knocking out multiple genes simultaneously. The use of HCT116 as a parental line also allows us to compare the 
TNRC6 lines directly with AGO knock out cell lines that were also created from HCT116 cells ((Chu et al. 2020), Y Chu, S Yakota, J Liu et al., 2021, accompanying manuscript).

The knockout of the TNRC6A was confirmed by western blot analysis (Supplementary Figure 1A). We did not possess an adequate antibody to detect TNRC6B and knockout of TNRCB protein expression was confirmed by mass spectrometry (Liu et al. 2019). The knockout of TNRC6 A was due to a point mutation that produced a frameshift while the knockout of TNRC6 B was achieved by a 95,481 base-pair deletion (Figure 1A).

TNRC6 A-/- or TNRC6 B-/- single knockout cells grew slower than wild cells (Liu et al. 2019). TNRC6 AB-/- double knockout cells were the slowest proliferating. We could not obtain a TNRC6 ABC-/- triple mutant, consistent with residual TNRC6 function being necessary for cell growth. To examine the effect of loss of TNRC6 $\mathrm{C}$ we used a pool of anti-TNRC6C duplex RNAs that knocked down greater than $90 \%$ of $T N R C 6 C$ expression (Supplementary Figure 1B).

\section{Effect of TNRC6 paralog expression on cell cycle}

To further evaluate the impact of the TNRC6 paralogs on cell proliferation, we examined the consequences of TNRC6 knockout on cell cycle. The TNRC6 A-/- and TNRC6 B-/knockout cell lines showed no significant changes throughout the cell cycle (Figure 1B). Double knockout TNRC6 AB-/- cells, had a significant increase in G2 phase in the TNRC6 AB-/- cells (Figure 1B). The change in cell cycle stage for the double knock out cells is consistent with the reduced cell growth seen in the TNRC6 AB-/- cells (Liu et al., 2019). 
Because we could not obtain triple knockout TNRC6 ABC-/- cells, we used a siRNA to knock down TNRC6C expression (Supplemental Figure 1B). As a control, we also transfected a noncomplementary duplex RNA, siGL2, into both wild-type HCT116 and TNRC6 AB-/- double knockout cells. We observed that cell growth was decreased by transfection of the anti-TNRC6C duplex RNA relative to wild-type cells but that knocking down TNRC6 $\mathrm{C}$ has little effect for TNRC6 AB-/- double knockout cells (Figure 1C).

When TNRC6 $\mathrm{C}$ alone is knocked down using an siRNA pool, the cell cycle does not change significantly relative to addition of the control duplex (Figure 1D). When both TNRC6A and TNRC6B are knocked out, the addition of either control or antiTNRC6C duplex RNA in complex with lipid dramatically alters the cell cycle. Transfection with lipid can stress cells. These data suggest that the loss of most function of the three TNRC6 paralogs may have a bigger impact when the cells are challenged by environmental change.

\section{Impact of TNRC6 knockout/knockdown on gene expression}

We used RNA sequencing (RNAseq) of whole cells to evaluate the impact of knocking down or knocking out TNRC6A, TNRC6B, and TNRC6C on overall gene expression (Figure 2). Read depth was consistent across all samples. Knocking out TNRC6A had a greater effect on gene expression than knocking out TNRC6B or knocking down TNRC6C (Figure 2A). The TNRC6 AB-/- double knockout has a larger effect than the single knockout cell lines (Figure 2A). The greatest impact on gene expression was 
observed for the combination of TNRC6 AB-/- knockout and TNRC6C siRNA-mediated knockdown (Figure 2A).

We have previously used enhanced crosslinking immunoprecipitation (eCLIP) (Van Nostrand et al. 2016) to identify locations within the transcriptome where AGO2 binds (Chu et al., 2020). Genes that host these sites are candidates for regulating gene expression because significant AGO2 binding is thought to be correlated with recognition of miRNAs (Lewis et al. 2003; Friedman et al. 2009; Gebert and MacRae 2019; Chu et al. 2020; Eisen et al. 2020). These regions were identified by clusters of RNAseq reads that were not present or not significantly enriched when compared to parallel experiments using AGO2 knockout cells or a size-matched input sample.

The standard mechanism for endogenous miRNA regulation in mammalian cells suggests that regulation is through interactions within the 3'-untranslated region (3'UTR). Therefore, we examined mRNAs that possessed read clusters within their 3'UTRs. We then measured the effect of TNRC6 loss on the expression of these genes in knockout versus wild-type cells (Figure 2B).

In all cell lines examined, only a small fraction of gene expression changes (Figure 2A) were associated with a significant AGO2 binding clusters (Figure 2B). As we had observed for overall gene expression, the number of genes with altered expression was less in single knockout cells, greater in double knockout cells, and greatest in the TNRC6 AB-/- siTNRC6C cell line. Once again, the TNRC6 A-/- knockout had a bigger effect on expression than the TNRC6 B-/- knockout or siTNRC6C knockdown. 
A standard assumption of miRNA action is that binding of an AGO:miRNA complex within the 3'-UTR will repress gene expression (Friedman et al. 2009; Guo et al. 2010; Jonas and Izaurralde 2015; Gosline et al. 2016; Gebert and MacRae 2019) and that knocking out $A G O$ variants should increase gene expression. While reducing expression of RNAi factors like the TNRC6 variants would be expected to produce a complex mix of gene expression changes - some direct and some indirect - genes that associate with AGO2 would be expected to be de-repressed when critical RNAi factors are knocked out or knocked down.

We observed, however, that regardless of whether we examine the expression of all genes (Figure 2A) or only genes with AGO binding clusters (Figure 2B), that similar numbers of genes were associated with up- and down- regulation. These data indicate that there is no simple correlation between AGO2 occupancy and up- or downregulation of a transcript. We then used volcano plots to visualize cluster significance and fold change of individual genes (Figure 2C). Once again, the TNRC6 A-/- cell line showed more profound changes than TNRC6 B-/- cells. The TNRC6 AB-/- cells or TNRC6 AB-/- siC cells showed much greater effects than the single gene knockout cells, both in terms of the number of genes changed and the magnitude of gene expression changes. Cluster significance, the indication of AGO2 occupancy, was not associated primarily with up or down regulation regardless of which knockout cell line is examined.

\section{Comparing the impact of AGO and TNRC6 knockouts on global gene expression}


The TNRC6 paralogs are important binding partners for AGO proteins (Kalantari et al. 2016b; Hicks et al. 2017). The scaffolding domains of TNRC6 facilitate the recruitment of effector proteins for mRNA degradation (Piao et al. 2010; Chekulaeva et al. 2011; Fabian et al. 2011; Hicks et al. 2017) or transcriptional activation (Hicks et al. 2017; Liu et al. 2018; Liu et al. 2019). Because of the partnership between AGO and TNRC6 we hypothesized that many gene expression changes would be shared between TNRC6 and AGO knockout cells and be the best candidates as endogenous control points for regulation by miRNAs. It is also possible, however, that AGO and TNRC6 proteins may play independent roles. To evaluate these hypotheses and identify candidate genes, we compared the impact on gene expression of knocking out AGO and TNRC6 proteins (Figure 3).

We focused on genes that had significant AGO2-binding clusters within their 3'UTRs (Chu et al. 2020) and compared the gene expression changes in TNRC6 AB-/-, TNRC6 AB-/- siTNRC6C, AGO12-/-, and AG0123-/- cells relative to wild-type HCT116 cells (Figure 3A). When examining large datasets, it is important to prioritize outputs. We reasoned genes that genes showing expression changes in multiple cell lines would be the best candidates for physiologically relevant gene regulation. Gene expression changes due to experimental noise or artefacts from RNAseq are least likely when the changes occur in multiple cell lines. We recognize that these stringent criteria may overlook some candidates, but they facilitate focusing on a manageable number of genes for further analysis.

We identified sixty-seven genes with AGO2 binding clusters and significantly changed gene expression (FDR $<0.05,-0.6>\log _{2}$ Fold Change $>0.6$ ) that were shared in 
all of the four cell lines (Figure 3A). These sixty-seven genes included examples of both up- and down-regulation, with thirty-six genes increasing expression and thirty-one genes with reduced expression.

We then used heat map analysis to sort these genes according to altered gene expression and to extend the comparison to our AGO knockout cell lines. (Figure 3B). Of the nine cell lines examined, the siTNRC6C knockdown cells showed the least change and no obvious correlation for up- or down- regulation. Of the remaining TNRC6 knockout cell lines, gene expression changes were weakest in TNRC6 B-/- cells, stronger in TNRC6 A-/- cells, and strongest in the TNRC6 AB-/- and TNRC6 AB-/- siC cells - a comparison reminiscent of our data for cell proliferation, cell cycle analysis, and global gene expression. For the eight knockout cell lines, genes that were upregulated in AGO knockout cells tended to be upregulated in TNRC6 knockout cells, while genes that were downregulated in $A G O$ knockout cells showed similar downregulation in the engineered TNRC6 cells (Figure 3B).

For comparison, we also examined gene expression changes in other overlapping cohorts of knockout cells. For example, the 95 genes that were only changed significantly in the TNRC6 AB-/- siTNRC6C cell lines (Figure 3A), did not show similar gene expression trends relative to the other cell types (Figure 4A). This result supports the conclusion that these gene expression changes are unrelated to perturbation of the RNAi pathway. Conversely, the 185 changes shared between the AG0123-/- and the TNRC6 AB-/- siTNRC6C mostly overlap (Figure 4B), suggesting that these genes are more likely to be regulated by RNAi (Figure 4B). 
When evaluating CLIP-seq data, it is essential to view the primary data to evaluate the characteristics of each cluster of reads to ensure the quality of the data and identify different classes of read cluster. Previously, we had focused our experimental validation of gene expression in AGO knockout cells on 22 representative genes with AGO2-binding clusters (Chu et al. 2020). These genes were chosen to represent differing species of highly significant cluster (single clusters versus multiple closely space clusters), and both up- and down-regulated genes. These cluster sites contained seed sequence complementary to well-expressed miRNAs.

We compared the gene expression of these twenty-two chosen genes in our nine knockout or knockout/knockdown datasets. Similar to the result observed with our sixtyseven gene overlapping cohort (Figure 4), the selected twenty-two genes showed a similar rank order of gene expression change regardless of whether AGO or TNRC6 variants were being knocked out (Figure 5A). As observed for the sixty-seven gene cohort, the siTNRC6C knockdown cells did not trend with the other cell lines, suggesting that the TNRC6C knockdown had the least impact on cells. These data demonstrate that the broad trends correlating the impact of gene expression of TNRC6 and AGO knockdown also apply to genes with strongest AGO2 association detected by eCLIP.

Quantitative PCR (qPCR) was performed to validate the RNAseq data (Figure 5B). Measurement of RNA samples from each cell line confirmed the trends observed the RNAseq data. These data suggest that the trends correlating AGO or TNRC6 knockout remain similar regardless of the shape of the RNA read cluster detected by eCLIP and RNAseq. 


\section{Impact of AGO and TNRC6 variants on alternative splicing}

RNAi has been suggested to have the potential to directly regulate splicing (Allo et al. 2009; Liu et al. 2012; Liu et al. 2015; Fuchs et al. 2021). In a related study, we have examined the impact of knocking out AGO variants on gene splicing (Y Chu, S Yakota,

J Liu et al., 2021, accompanying manuscript). We now examine the impact of knocking out TNRC6 paralogs on splicing to assess the involvement of TNRC6 on the regulation of endogenous splicing by miRNAs.

We evaluated the changes in splicing observed in our knockout cell lines. Venn diagrams were used to visualize all skipped exon splicing events that were changed in AG0123-/-, AGO12-/-, TNRC6AB-/-, and TNRC6AB-/- siTNRC6C cell lines (Figure 6AB). Changes that were observed in all four lines were awarded the highest priority for analysis because we reasoned that shared events would be most likely to have physiological relevance.

We found that fifteen skipped exon splicing events are shared between the four cell lines (Figure 6A). Of those fifteen, only two genes (DEPDC1 and EPB41L2) had significant AGO2 binding clusters located near affected introns (Figure 6B). Visual inspection of the sashimi plots for $D E P D C 1$ showed an increase in exon skipping in the TNRC6 $A B-/-$ and TNRC6 AB-/- siC cell lines relative to wildtype (Figure $6 \mathrm{C}$ ) while EPB41L2 sashimi plots showed a decrease in exon skipping for the knockout cell lines (Figure 6D). The splicing changes seen in the RNAseq data for DEPDC1 and EPB41L were validated by qPCR (Figure 6E). Splicing changes for EPB41L2 were further validated by PCR gel (Supplementary Figure 3). 
Our criteria that changes occur in all cell lines is restrictive. Intronic RNA is recovered at relatively low amounts and we recognized that our criteria might cause us to overlook some candidates. We chose, therefore, to examine the impact of TNRC6 knockouts on seven genes that our laboratory had already evaluated for splicing changes due to knockout of AGO proteins (Y Chu, S Yakota, J Liu et al., 2021, accompanying manuscript) (Figure 7). These seven genes were chosen because they had at least one AGO2 cluster near a significant splicing event locus within an intron and had a miRNA candidate complementary to a sequence within the AGO2 cluster.

Of the seven genes analyzed, our RNAseq data for TNRC6 knockout cells showed significant changes in alternative splicing for five genes in either the TNRC6 $A B-/-$ or $T N R C 6 A B-/-$ siC cells. We evaluated splicing changes by reverse transcriptase PCR (Figure 7AB). For five genes, FKBP14, KIF21A, PHLDB1, RUBCN, and TBC1D5, RT-PCR data confirmed significant splicing changes in both TNRC6 AB-/- and AGO 123-/- cells. (Figure 7B). For FKBP14 and KIF21A, qPCR data confirmed splicing changes in TNRC6 AB-/- and TNRC6 AB-/- siC (Supplementary Figure 4). Two genes, APIP and PPIP5K2, did not have significant detected changes in RNAseq data and we also did not observe significant changes in PCR (Figure 7AB).

Two genes, RUBCN and FKBP14, that showed splicing changes in the TNRC6 knockout cells were examined in more detail in an accompanying study (Y Chu, S Yakota, J Liu et al., 2021, accompanying manuscript). Their splicing was shown to be modulated by miRNA mimics or anti-miRNA oligonucleotides that target the site for AGO2 association determined through eCLIP. These data reinforce the conclusion the suggestion that the genes are targets for endogenous small RNAs. 
bioRxiv preprint doi: https://doi.org/10.1101/2021.02.09.430449; this version posted February 9, 2021. The copyright holder for this preprint (which was not certified by peer review) is the author/funder, who has granted bioRxiv a license to display the preprint in perpetuity. It is made available under aCC-BY-NC-ND 4.0 International license. 


\section{DISCUSSION}

\section{TNRC6 paralogs and RNAi}

The three human TNRC6 paralogs, TNRC6A, TNRC6B, and TNRC6C, play important roles in RNAi (Baillat and Shiekhattar 2009; Niaz and Hussain 2018). The complex between a small RNA and AGO proteins recognizes the target sequences within cellular RNA, while the three multi-domain TNRC6 paralogs bind to AGO and act as scaffolds to promote association with proteins that modulate function. While the three protein paralogs are $\sim 40 \%$ identical, their potential for unique or redundant activities has not been determined. Neither has the extent to which their impact on endogenous gene expression overlaps the impact of AGO proteins.

We had previously investigated the impact of knocking out TNRC6 paralogs on the ability of synthetic duplex RNAs to control translation and splicing (Liu et al., 2019). In those studies, we found that knocking out TNRC6 expression did not affect inhibition of translation or splicing by fully or highly complementary synthetic duplex RNAs but did reverse the action of synthetic miRNA mimics. Here we use knockout cell lines and an efficient siRNA pool that reduces TNRC6C expression to analyze the role of TNRC6 expression on global gene expression.

\section{Redundancy or independence: Roles for TNRC6 paralogs}

We had previously used knockout cells to demonstrate that the loss of both TNRC6A and TNRC6B was required to affect gene silencing by synthetic duplex RNAs (Liu et al. 2019). Alone, TNRC6A and TNRC6B were replaceable. Consistent with this observation, we now observe knocking out TNRC6A or TNRC6B alone has no 
significant effect on the cell cycle (Figure 1). Larger impacts on cell cycle were observed in the TNRC6 AB-/- double knockout cell line or TNRC6 AB-/- siTNRC6C cells

(Figure 2). Analysis of gene expression or alternative splicing revealed similar results. Blocking expression of two or three TNRC6 paralogs affected expression (Figure 3) or alternative splicing (Figure 5) of many more genes than did blocking expression of TNRC6A, TNRC6B, or TNRC6C alone. The conclusion that TNRC6 paralogs have largely redundant functions regulating endogenous gene expression is consistent with our previous observation of redundant function when modulating the effects of designed synthetic RNAs.

While the single knockouts showed relatively little change relative to double knockout cells, we did observe substantially larger number of genes with altered expression in the TNRC6 A-/- cells than in TNRC6 B-/- cells. These data may indicate that that TNRC6A plays a unique role in regulating expression of a subset of genes. Alternatively, TNRC6A is the most highly expressed paralog (Supplementary Figure 2) and its loss from the pool of TNRC6 protein may have the biggest impact.

\section{How do TNRC6 paralogs affect regulation by RNAi?}

We have used eCLIP to identify sites for AGO2 binding within cytoplasmic (Chu et al., 2020) and nuclear (Y Chu, S Yakota, J Liu et al., 2021, accompanying manuscript). RNA and used these data to understand how AGO binding correlates with gene expression and splicing at these sites. One conclusion from these studies was that, contrary to the standard expectation that AGO2 binding within a 3'-UTR should be 
associated with gene repression, we observed that genes with significant association to AGO2 showed by up- and down-regulation upon gene knockouts.

Here we report that the effects of knocking out TNRC6 paralogs on the expression of genes with significant AGO2 binding sites yield remarkably similar results

(Figure 3). We can make several conclusions from these data: 1) TNRC6 proteins are largely redundant, although knockout of TNRC6 A has the largest effect. As additional TNRC6 paralogs are removed, effects become greater; 2) The similarity of up- and down-regulated genes reveals the remarkable extent to which AGO and TNRC6 proteins function as partners to control gene expression; 3) As with AGO knockout cells, knocking out TNRC6 paralogs has an unpredictable effect on gene expression. The fact that AGO2 has a significant association with a 3'-UTR cannot be assumed to lead to gene up-regulation when AGO or TNRC6 proteins are removed from cells

We have not resolved whether the changes in gene expression we observe are due to direct effects of miRNAs binding to sites where AGO2 association is detected or indirect effects. Because of the lack of predictable correlation with gene repression or up-regulation, such studies are not straightforward and will be a subsequent focus of research. It is clear from the data, however, that the genes we identify are being controlled by a common RNAi axis that requires expression of both AGO and TNRC6. The fact that we observe both increased and decreased expression at genes with AGO2 association within their 3'-untranslated regions supports our previous conclusion from AGO knockout cells that AGO2 occupancy is not sufficient to infer repression of a target transcript and emphasize the complexity of RNAi function. 


\section{Impact of TNRC6 on alternative splicing}

While RNAi is often assumed to be a cytoplasmic mechanism in mammalian cells (Zeng and Cullen 2002), RNAi protein factors and miRNAs also exist in cell nuclei (Gagnon et al. 2014). Functional evidence showing robust control of transcription and splicing by synthetic duplex RNAs (Allo et al. 2009; Liu et al. 2012; Liu et al. 2015; Kalantari et al. 2016a) has suggested the potential for nuclear RNAi to be a natural regulatory mechanism, but persuasive experimental evidence for control of endogenous transcription or spicing has been elusive. In addition, previous studies using synthetic RNAs had shown that TNRC6 is not required for highly complementary synthetic small RNA to influence differential splicing (Liu et al. 2018).

In an accompanying paper, we investigate the impact of endogenous miRNAs and RNAi on alternative splicing (Y Chu, S Yakota, J Liu et al., 2021, accompanying manuscript). We identify sites of AGO2 binding using the same eCLIP dataset used here and correlate AGO2 binding with changes in splicing upon knocking out AGO1, AGO2, and AGO3. We observe changes in splicing and show that splicing can be manipulated by synthetic miRNAs or anti-miRs designed based on predictions of miRNAs that target sites identified by eCLIP.

We now show that knocking TNRC6 variants also affect alternative splicing. As with our AGO datasets, only a relatively small number of candidate splicing events are identified. However, of this small number, there was substantial overlap between our TNRC6 and AGO data, supporting belief they are due to a common RNAi-related pathway. The expression of two of the genes with splicing changes in both AGO-/- and 
TNRC6-/- datasets, RUBCN and FKBP14, could be manipulated by miRNA mimics or antimiRs designed to predicted target sites.

These data suggest that miRNAs have the potential to control endogenous splicing. We had previously reported that duplex RNAs that control splicing did not require expression of TNRC6 (Liu et al., 2019). These RNAs, however, were either fully or almost fully complementary to their target sites within intronic RNA. The scaffolding function of TNRC6 acts to bridge AGO proteins, increasing the cooperativity of binding and allowing imperfectly paired miRNAs to associate with target sequences more tightly (Elkayam et al. 2017). It is possible that, while TNRC6 is not necessary for recognition of highly complementary duplex RNAs, it is necessary for the activity of mixtures of imperfectly complementary miRNAs that act in concert to control endogenous gene expression.

Our data also suggest that AGO and TNRC6 affect the splicing of a relatively small subset of proteins. This outcome is consistent with the conclusion that RNAmediated regulation of splicing is a minor regulatory mechanism in HCT116 cells. RNAimediated regulation of splicing may also be more pervasive in other cell types, cells grown under more demanding environment conditions, during cell development, or during cells involved in disease. Alternatively, intronic RNA is present at relatively low steady state levels (Clement et al. 1999; Mortazavi et al. 2008) and therefore less detectable. Because of our stringent conditions for identifying candidates for AGO2 binding and splicing change, we may be overlooking genes where RNA-directed modulation of splicing is biologically significant yet undetected by our approach. 


\section{Conclusions}

Scaffolding proteins play complex roles bringing other proteins, RNA, or DNA together.

The TNRC6 family proteins a multi-domain model for understanding the potential of scaffolding proteins to organize molecular function. (Shaw and Filbert 2009) We observe a strong overlap between the changes in gene expression upon knockout of TNRC6 or AGO proteins, consistent with the partnership of these proteins during RNAi. In our HCT116 model cell line, at least, that partnership does not produce predictable changes in gene expression at sites within target RNAs where AGO2 binds. It is clear from our data that TNRC6 plays an important role in controlling gene expression, but there remains much to learn about how it acts in concert with AGO2 and the possibility that it may play significant roles independent of AGO2. 


\section{MATERIALS AND METHODS}

\section{Cell Culture}

Wild-type HCT116 cells were obtained from Horizon Discovery. HCT116 cells containing knock out modifications to the TNRC6A, TNRC6B, and TNRC6A \& TNRCB genes were purchased from GenScript. All cell lines were cultured in McCoy's 5A medium (Sigma-Aldrich) supplemented with $10 \% \mathrm{FBS}$ (Sigma-Aldrich) in $37^{\circ} \mathrm{C} 5 \% \mathrm{CO}_{2}$. For cell counting, cells were mixed together with equal volume of trypan blue (Sigma) and were counted using cell counter (TC20 ${ }^{\mathrm{TM}}$ Automated Cell Counter; Bio-Rad).

\section{Transfections}

All transfections used Lipofectamine RNAi MAX (Invitrogen). For transfections, cells were seeded into six-well plates at 150 thousand cells per well for wild type, TNRC6 A-/and TNRC6 B-/.. TNRC6 AB-/- cells were seeded at 250 thousand cells per well due to the slowed growth rate of these cells. Cells were transfected as described in Liu et al., 2019.

\section{PI Staining and FACS}

Cells were harvested at $90 \%$ confluency for cell cycle analysis by propidium iodide (PI) staining. Cells were harvested using 1 X Trypsin-EDTA (Sigma) and washed with PBS. To fix cells, they were suspended in PBS at a concentration of $2 \times 10^{6}$ cells per $\mathrm{mL}$ and added to an equal volume of $100 \%$ ethanol while vortexing. Cells were then incubated at $-20^{\circ} \mathrm{C}$ for 24 hours to 1 month. To prepare cells for staining with $\mathrm{PI}$, they were 
washed three times with PBS to ensure all ethanol was removed. Cells were suspended in staining buffer $\left(0.1 \%\right.$ Triton $X, 20 \mathrm{ug} / \mathrm{mL} \mathrm{PI}$, and $20 \mu \mathrm{g} / \mathrm{mL}$ RNAse A) at $2 \times 10^{6}$ cells per $\mathrm{mL}$. Stained cells are incubated at $37^{\circ} \mathrm{C}$ for 15 mins. Cell were then stored at $4^{\circ} \mathrm{C}$ and protected from the light. Cells were run within 48 hours at the UTSW Flow Cytometry Facility on a Caliber. Data was then analyzed using FlowJo software.

RNA extraction, RNA sequencing, \& enhanced crosslinking immunoprecipitation sequencing (eCLIP)

Whole cell RNA was extracted from cells harvested with trypsin at $90 \%$ confluency. RNeasy kit (Qiagen) was used purify the RNA for whole cell steady state mRNA sequencing. RNA sequencing was performed by the McDermott Center Next Generation Sequencing Core at UTSW as described in Chu et al, 2021. RNA sequencing data was analyzed in the same manner as Chu et al. 2021. Methods and analysis for eCLIP were described in Chu et al., 2020.

\section{qPCR and western blot}

Both qPCRs and western blots were performed as described in Liu et al., 2019.

\section{Splicing analysis by gel electrophoresis and qPCR}

Total RNA was extracted from HCT116 wild-type, TNRC6 knockout cells, and treated with DNase I (Worthington Biochemical) at $25^{\circ} \mathrm{C}$ for $20 \mathrm{~min}, 75^{\circ} \mathrm{C}$ for $10 \mathrm{~min}$. Reverse transcription was performed using high-capacity reverse transcription kit (Applied 
Biosystems) per the manufacturer's protocol. $2.0 \mu \mathrm{g}$ of total RNA was used per $20 \mu \mathrm{l}$ of reaction mixture.

For gel electrophoresis analysis, PCR amplification was performed as following; $95{ }^{\circ} \mathrm{C} 3 \mathrm{~min}$ and $95{ }^{\circ} \mathrm{C} 30 \mathrm{~s}, 60^{\circ} \mathrm{C} 40 \mathrm{~s}, 72^{\circ} \mathrm{C} 30 \mathrm{~s}$ for 35 cycles. The PCR products were separated by $1.5 \%$ agarose gel electrophoresis. The bands were quantified by using ImageJ software.

In qPCR analysis for splicing changes by using double strand RNAs and miRNA mimics, PCR was performed on a Biorad CFX384 Real-Time System using iTaq SYBR Green Supermix (BioRad). PCR reactions were done in triplicates at $55^{\circ} \mathrm{C} 2 \mathrm{~min}, 95^{\circ} \mathrm{C}$ 3 min and $95{ }^{\circ} \mathrm{C} 20 \mathrm{~s}, 60{ }^{\circ} \mathrm{C}$ 45s for 40 cycles in an optical 384-well plate. The expression level was compared between exon included spliceform and exon excluded spliceform. PCR primers were shown in Supplementary Table 3.

\section{mRNA quantification}

RNA standards of TNRC6 A, TNRC6 B, TNRC6 C, GAPDH, and MYC synthesized by in vitro transcription from cDNA using SP6 Megascript Kit (ThermoFisher). Primers were designed following the manufactured instructions and are listed in Supplementary Table 1. RNA purity was measured by Bioanalyzer (Agilent, Santa Clara, CA, USA). Purified standard RNA was serially diluted to $100,1 \times 10^{3}, 1 \times 10^{4}, 1 \times 10^{5}, 1 \times 10^{6}, 1 \times 10^{7}, 1 \times 10^{8}$ and $1 \times 10^{9}$ and used to construct a standard curve for qPCR efficiency following reverse transcription.

Experimental RNA for mRNA quantification was extracted from disassociated and counted cells with seven repeated Trizol/chloroform precipitations. For both the 
experimental and RNA standard, $0.5 \mathrm{ml}$ DNA LoBind Tubes (Eppendorf) coated in nuclease free water supplemented with RNase Inhibitor and salmon sperm DNA were used to prevent loss of RNA to tube binding.

Total RNA from HCT116 WT, TNRC6 A-/-, TNRC6 B-/-, and TNRC6 AB-/- was treated with DNase I (Worthington Biochemical) at $25^{\circ} \mathrm{C}$ for $20 \mathrm{~min}, 75^{\circ} \mathrm{C}$ for $10 \mathrm{~min}$. Reverse transcription was performed using high-capacity reverse transcription kit (Applied Biosystems) per the manufacturer's protocol. PCR was performed on a Biorad CFX384 Real-Time System using iTaq SYBR Green Supermix (BioRad). PCR reactions were done in triplicates at $55^{\circ} \mathrm{C} 2 \mathrm{~min}, 95^{\circ} \mathrm{C} 3 \mathrm{~min}$ and $95^{\circ} \mathrm{C} 20 \mathrm{~s}, 60{ }^{\circ} \mathrm{C} 45 \mathrm{~s}$ for 40 cycles in an optical 384-well plate. The CT values were plotted against the number of molecules (log10-scale) and analyzed with linear regression to calculate the copy number per cell.

\section{DATA AVAILABILITY}

All high-throughput sequencing data generated for this study (RNAseq, eCLIP) have been deposited in Gene Expression Omnibus under accession number GSE162749.

\section{SUPPLEMENTAL MATERIAL}

Supplemental material is available for this article.

\section{ACKNOWLEDGEMENTS}

The authors thank Dr. Joshua Mendell for the gift of HCT116:AGO2 knock out cells and Dr. Jay Nelson for anti-AGO antibody 3148. DRC was supported by the National 
Institutes of Health (NIH) (GM106151) and the Robert Welch Foundation (I-1244). DRC holds the Rusty Kelley Professorship in Medical Science. STJ is supported by an NIH predoctoral fellowship (5 F31 EY030336-03).

Author contributions: D.R.C. wrote the manuscript and supervised the experiments. S.T.J., Y.C., and J.L. performed the experiments and assisted in writing the manuscript.

\section{DECLARATION OF INTERESTS}

The authors have no competing interests. 


\section{REFERENCES}

Albert TK, Lemaire M, van Berkum NL, Gentz R, Collart MA, Timmers HT. 2000. Isolation and characterization of human orthologs of yeast CCR4-NOT complex subunits. Nucleic Acids Res 28: 809-817.

Allo M, Buggiano V, Fededa JP, Petrillo E, Schor I, de la Mata M, Agirre E, Plass M, Eyras E, Elela SA et al. 2009. Control of alternative splicing through siRNA-mediated transcriptional gene silencing. Nat Struct Mol Biol 16: 717-724.

Baillat D, Shiekhattar R. 2009. Functional dissection of the human TNRC6 (GW182-related) family of proteins. Mol Cell Biol 29: 4144-4155.

Behm-Ansmant I, Rehwinkel J, Doerks T, Stark A, Bork P, Izaurralde E. 2006. mRNA degradation by miRNAs and GW182 requires both CCR4:NOT deadenylase and DCP1:DCP2 decapping complexes. Genes Dev 20: 1885-1898.

Briskin D, Wang PY, Bartel DP. 2020. The biochemical basis for the cooperative action of microRNAs. Proc Natl Acad Sci U S A 117: 17764-17774.

Broderick JA, Salomon WE, Ryder SP, Aronin N, Zamore PD. 2011. Argonaute protein identity and pairing geometry determine cooperativity in mammalian RNA silencing. RNA 17: 1858-1869.

Chekulaeva M, Mathys H, Zipprich JT, Attig J, Colic M, Parker R, Filipowicz W. 2011. miRNA repression involves GW182-mediated recruitment of CCR4-NOT through conserved Wcontaining motifs. Nat Struct Mol Biol 18: 1218-1226.

Chu Y, Kilikevicius A, Liu J, Johnson KC, Yokota S, Corey DR. 2020. Argonaute binding within 3'-untranslated regions poorly predicts gene repression. Nucleic Acids Res 48: 7439-7453.

Clement JQ, Qian L, Kaplinsky N, Wilkinson MF. 1999. The stability and fate of a spliced intron from vertebrate cells. RNA 5: 206-220.

Collart MA. 2016. The Ccr4-Not complex is a key regulator of eukaryotic gene expression. Wiley Interdiscip Rev RNA 7: 438-454.

Eisen TJ, Eichhorn SW, Subtelny AO, Bartel DP. 2020. MicroRNAs Cause Accelerated Decay of Short-Tailed Target mRNAs. Mol Cell 77: 775-785 e778.

Elkayam E, Faehnle CR, Morales M, Sun J, Li H, Joshua-Tor L. 2017. Multivalent Recruitment of Human Argonaute by GW182. Mol Cell 67: 646-658 e643.

Eulalio A, Tritschler F, Izaurralde E. 2009. The GW182 protein family in animal cells: new insights into domains required for miRNA-mediated gene silencing. RNA 15: 1433-1442.

Eystathioy T, Chan EK, Tenenbaum SA, Keene JD, Griffith K, Fritzler MJ. 2002. A phosphorylated cytoplasmic autoantigen, GW182, associates with a unique population of human mRNAs within novel cytoplasmic speckles. Mol Biol Cell 13: 1338-1351.

Fabian MR, Cieplak MK, Frank F, Morita M, Green J, Srikumar T, Nagar B, Yamamoto T, Raught B, Duchaine TF et al. 2011. miRNA-mediated deadenylation is orchestrated by GW182 through two conserved motifs that interact with CCR4-NOT. Nat Struct Mol Biol 18: 1211-1217.

Fabian MR, Mathonnet G, Sundermeier T, Mathys H, Zipprich JT, Svitkin YV, Rivas F, Jinek M, Wohlschlegel J, Doudna JA et al. 2009. Mammalian miRNA RISC recruits CAF1 and PABP to affect PABP-dependent deadenylation. Mol Cell 35: 868-880.

Friedman RC, Farh KK, Burge CB, Bartel DP. 2009. Most mammalian mRNAs are conserved targets of microRNAs. Genome Res 19: 92-105. 
Fuchs A, Riegler S, Ayatollahi Z, Cavallari N, Giono LE, Nimeth BA, Mutanwad KV, Schweighofer A, Lucyshyn D, Barta A et al. 2021. Targeting alternative splicing by RNAi: from the differential impact on splice variants to triggering artificial pre-mRNA splicing. Nucleic Acids Res 49: 1133-1151.

Gagnon KT, Li L, Chu Y, Janowski BA, Corey DR. 2014. RNAi factors are present and active in human cell nuclei. Cell Rep 6: 211-221.

Gebert LFR, MacRae IJ. 2019. Regulation of microRNA function in animals. Nat Rev Mol Cell Biol 20: 21-37.

Gosline SJ, Gurtan AM, JnBaptiste CK, Bosson A, Milani P, Dalin S, Matthews BJ, Yap YS, Sharp PA, Fraenkel E. 2016. Elucidating MicroRNA Regulatory Networks Using Transcriptional, Post-transcriptional, and Histone Modification Measurements. Cell Rep 14: $310-319$.

Guo H, Ingolia NT, Weissman JS, Bartel DP. 2010. Mammalian microRNAs predominantly act to decrease target mRNA levels. Nature 466: 835-840.

Hicks JA, Li L, Matsui M, Chu Y, Volkov O, Johnson KC, Corey DR. 2017. Human GW182 Paralogs Are the Central Organizers for RNA-Mediated Control of Transcription. Cell Rep 20: 1543-1552.

Jonas S, Izaurralde E. 2015. Towards a molecular understanding of microRNA-mediated gene silencing. Nat Rev Genet 16: 421-433.

Kalantari R, Chiang CM, Corey DR. 2016a. Regulation of mammalian transcription and splicing by Nuclear RNAi. Nucleic Acids Res 44: 524-537.

Kalantari R, Hicks JA, Li L, Gagnon KT, Sridhara V, Lemoff A, Mirzaei H, Corey DR. $2016 b$. Stable association of RNAi machinery is conserved between the cytoplasm and nucleus of human cells. RNA 22: 1085-1098.

Lazzaretti D, Tournier I, Izaurralde E. 2009. The C-terminal domains of human TNRC6A, TNRC6B, and TNRC6C silence bound transcripts independently of Argonaute proteins. RNA 15: 1059-1066.

Lewis BP, Shih IH, Jones-Rhoades MW, Bartel DP, Burge CB. 2003. Prediction of mammalian microRNA targets. Cell 115: 787-798.

Liu J, Hu J, Corey DR. 2012. Expanding the action of duplex RNAs into the nucleus: redirecting alternative splicing. Nucleic Acids Res 40: 1240-1250.

Liu J, Hu J, Hicks JA, Prakash TP, Corey DR. 2015. Modulation of Splicing by Single-Stranded Silencing RNAs. Nucleic Acid Ther 25: 113-120.

Liu J, Liu Z, Corey DR. 2018. The Requirement for GW182 Scaffolding Protein Depends on Whether Argonaute Is Mediating Translation, Transcription, or Splicing. Biochemistry 57: 5247-5256.

Liu Z, Johnson ST, Zhang Z, Corey DR. 2019. Expression of TNRC6 (GW182) Proteins Is Not Necessary for Gene Silencing by Fully Complementary RNA Duplexes. Nucleic Acid Ther 29: 323-334.

Mortazavi A, Williams BA, McCue K, Schaeffer L, Wold B. 2008. Mapping and quantifying mammalian transcriptomes by RNA-Seq. Nat Methods 5: 621-628.

Niaz S, Hussain MU. 2018. Role of GW182 protein in the cell. Int J Biochem Cell Biol 101: 2938.

Nishi K, Nishi A, Nagasawa T, Ui-Tei K. 2013. Human TNRC6A is an Argonaute-navigator protein for microRNA-mediated gene silencing in the nucleus. RNA 19: 17-35. 
Pfaff J, Hennig J, Herzog F, Aebersold R, Sattler M, Niessing D, Meister G. 2013. Structural features of Argonaute-GW182 protein interactions. Proc Natl Acad Sci U S A 110: E3770-3779.

Piao X, Zhang X, Wu L, Belasco JG. 2010. CCR4-NOT deadenylates mRNA associated with RNA-induced silencing complexes in human cells. Mol Cell Biol 30: 1486-1494.

Sarshad AA, Juan AH, Muler AIC, Anastasakis DG, Wang X, Genzor P, Feng X, Tsai PF, Sun HW, Haase AD et al. 2018. Argonaute-miRNA Complexes Silence Target mRNAs in the Nucleus of Mammalian Stem Cells. Mol Cell 71: 1040-1050 e1048.

Shaw AS, Filbert EL. 2009. Scaffold proteins and immune-cell signalling. Nat Rev Immunol 9: 47-56.

Suzawa M, Noguchi K, Nishi K, Kozuka-Hata H, Oyama M, Ui-Tei K. 2017. Comprehensive Identification of Nuclear and Cytoplasmic TNRC6A-Associating Proteins. J Mol Biol 429: 3319-3333.

Takimoto K, Wakiyama M, Yokoyama S. 2009. Mammalian GW182 contains multiple Argonaute-binding sites and functions in microRNA-mediated translational repression. RNA 15: 1078-1089.

Van Nostrand EL, Pratt GA, Shishkin AA, Gelboin-Burkhart C, Fang MY, Sundararaman B, Blue SM, Nguyen TB, Surka C, Elkins K et al. 2016. Robust transcriptome-wide discovery of RNA-binding protein binding sites with enhanced CLIP (eCLIP). Nat Methods 13: 508-514.

Zeng Y, Cullen BR. 2002. RNA interference in human cells is restricted to the cytoplasm. RNA 8: $855-860$. 


\section{FIGURE LEGENDS}

FIGURE 1. Effect of loss of TNRC6A, TNRC6B, or TNRC6C expression on cell cycle and cell proliferation. $(A)$ Diagram of TNRC6A, TNRC6B, and TNRC6C proteins, with known motifs, knockout mutations, and deletions. $(B)$ Percentage of cells in each stage of the cell cycle. $(C)$ Growth curve for cell lines transfected with anti-TNRC6C siRNA. (C) Percentage of cells in each stage of the cell cycle for transfected cell lines wild type after transfection with siTNRC6C, or control duplex siGL2. * $p$-value $>0.05 ;{ }^{* *} p$-value $>$ $0.01 .{ }^{* * *} p$-value $>0.001$

FIGURE 2. Association of AGO2 protein binding and gene expression in TNRC6 knockout cells. (A) Total number of significantly up- or down- regulated genes in knockout cell lines. (B) Total number of significantly up- or down- regulated genes in knockout cell lines. that overlap with AGO2 binding sites in coding sequences (CDS) and in the $3^{\prime}$ untranslated regions (3'UTR). (C) Volcano plots of gene expression in TNRC6 knockout cell lines.

FIGURE 3. Consistent variation for gene expression changes in TNRC6 and AGO knockout cells. (A) Venn diagram showing the overlap of gene expression changes associated with AGO2 binding within 3'-UTRs. (B) Heatmap showing gene expression changes shared by TNRC6 and AGO knockout cell lines. 
FIGURE 4. Comparison of gene expression in TNRC6 and AGO knockout cells. (A) Heatmap of gene expression changes of 95 genes with AGO2 protein binding clusters that change significantly only in the TNRC6AB-/- knock out/siTNRC6C knockdown cells. (B) Heatmap of gene expression changes of 159 genes with AGO2 clusters that change significantly in TNRC6 AB-/- siTNRC6C and AGO123-/- cells.

FIGURE 5: Consistent variation of gene expression in cells with highly ranked AGO2 protein binding clusters. (A) Heatmap of gene expression changes from TNRC6 knockout and $A G O$ knockout cell lines from RNA sequencing for 22 cluster genes examined in Chu et al, 2020. (B) Heatmap of gene expression changes from TNRC6 knockout and $A G O$ knockout cell lines from RT-qPCR for 22 cluster genes examined in Chu et al, 2020.

FIGURE 6. Changes in alternative splicing in TNRC6 knockout cell lines. (A) Venn diagram of skipped exon splicing events. $(B)$ Venn diagram of skipped exon splicing events located near AGO2 binding clusters. $(C+D)$ sashimi plots for genes DEPDC1 and EPB41L2 that overlap between TNRC6 AB-/- and TNRC6 AB-/- siC RNAseq datasets in (B). (E) qPCR validation of skipped exon events in TNRC6 $A / B$ knockout and TNRC6 A/BKO/siC cells. Error bars represent standard deviation (SD). ${ }^{*} \mathrm{P}<0.05$; ${ }^{* *} \mathrm{P}<0.01 ;{ }^{* * *} \mathrm{P}<0.001$ compared with control cell by two tailed $t$-test. $(\mathrm{F})$ Semiquantitative PCR validation of skipped exon events in TNRC6 A/B KO cells and quantitation of the gel. 
FIGURE 7. Validating the effect of TNRC6 knockouts on alternative splicing. $(A)$ Semiquantitative PCR validation of skipped exon events in TNRC6 A/B knockout cells. (B) Quantitation of data shown in in part (A). (C) QPCR validation of skipped exon events in TNRC6 A/B knockout and TNRC6 A/B knockout/siCTNRC6 knockdown cells. Error bars represent standard deviation (SD). ${ }^{*} \mathrm{P}<0.05 ;{ }^{* *} \mathrm{P}<0.01 ;{ }^{* *} \mathrm{P}<0.001$ compared with control cell by two tailed $t$-test. 
A

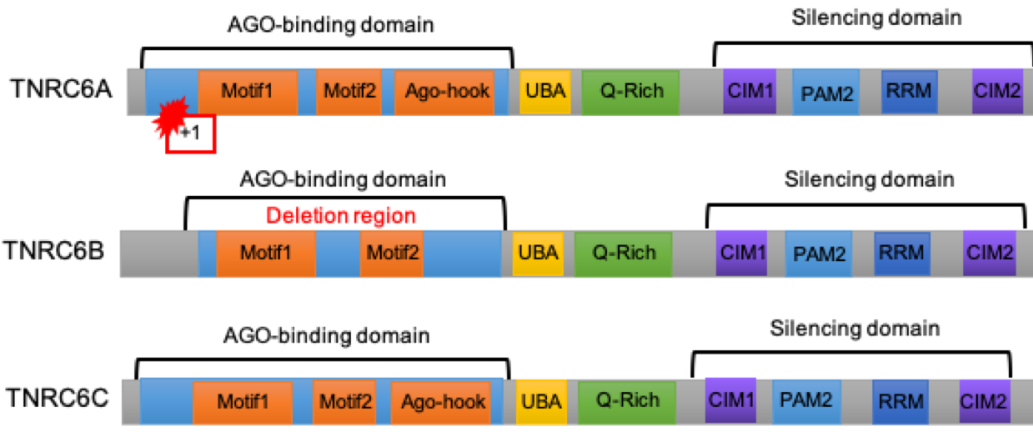

B

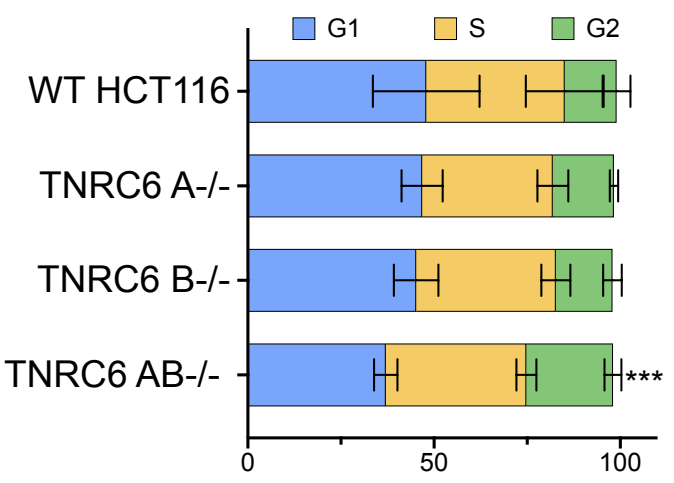

C

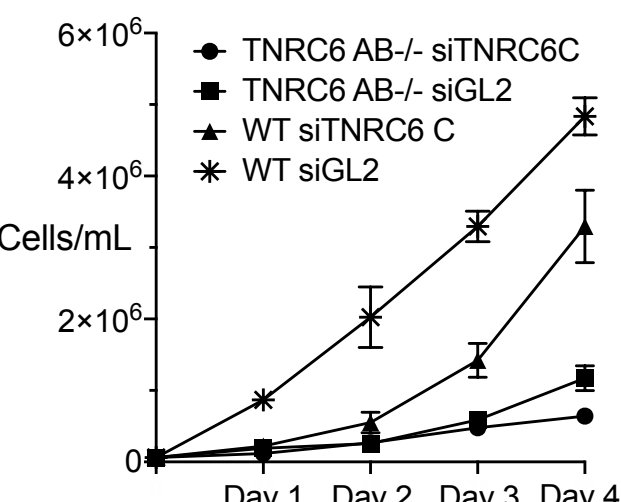

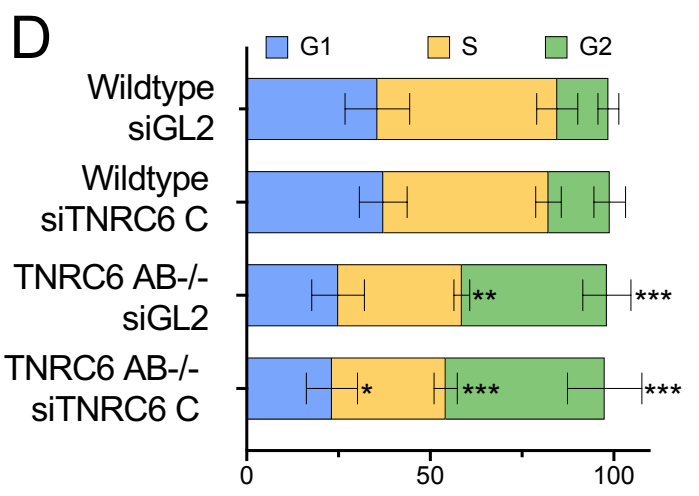

FIGURE 1. Effect of loss of TNRC6A, TNRC6B, or TNRC6C expression on cell cycle and cell proliferation. (A) Diagram of TNRC6A, TNRC6B, and TNRC6C proteins, with known motifs, knockout mutations, and deletions. (B) Percentage of cells in each stage of the cell cycle. (C) Growth curve for cell lines transfected with anti-TNRC6C siRNA. (C) Percentage of cells in each stage of the cell cycle for transfected cell lines wild type after transfection with siTNRC6C, or control duplex siGL2. * $p$-value > 0.05; ${ }^{* *} p$ value $>0.01 .{ }^{* * *} \mathrm{p}$-value $>0.001$. 
A
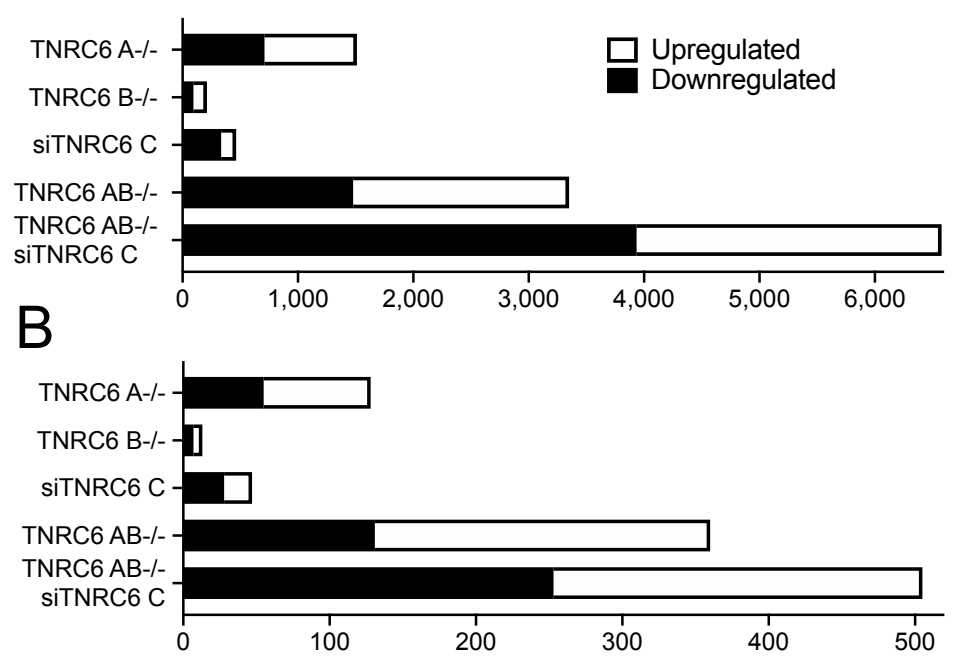

FIGURE 2. Association of AGO2 protein binding and gene expression in TNRC6 knockout cells. (A) Total number of significantly up- or downregulated genes in knockout cell lines. (B) Total number of significantly up- or down- regulated genes in knockout cell lines. that overlap with $\mathrm{AGO} 2$ binding sites in coding sequences (CDS) and in the 3' untranslated regions (3'UTR). (C) Volcano plots of gene expression in TNRC6 knockout cell lines.
C

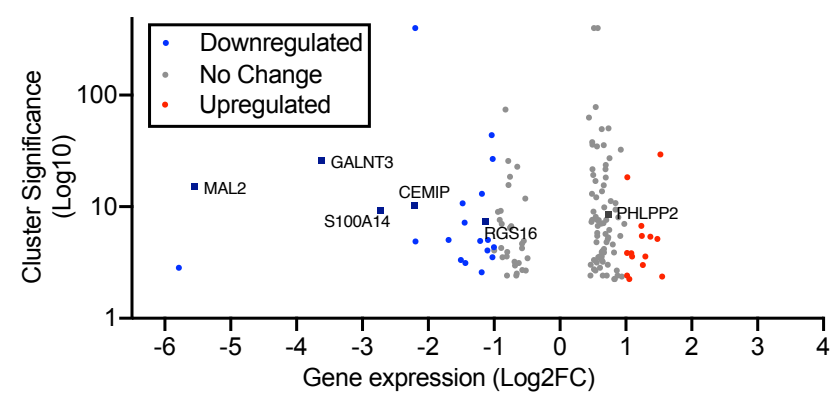

TNRC6 AB-/-

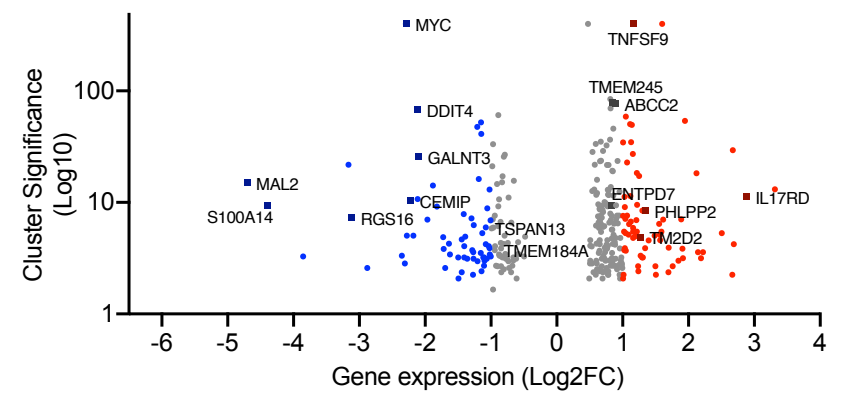

TNRC6 B-/-
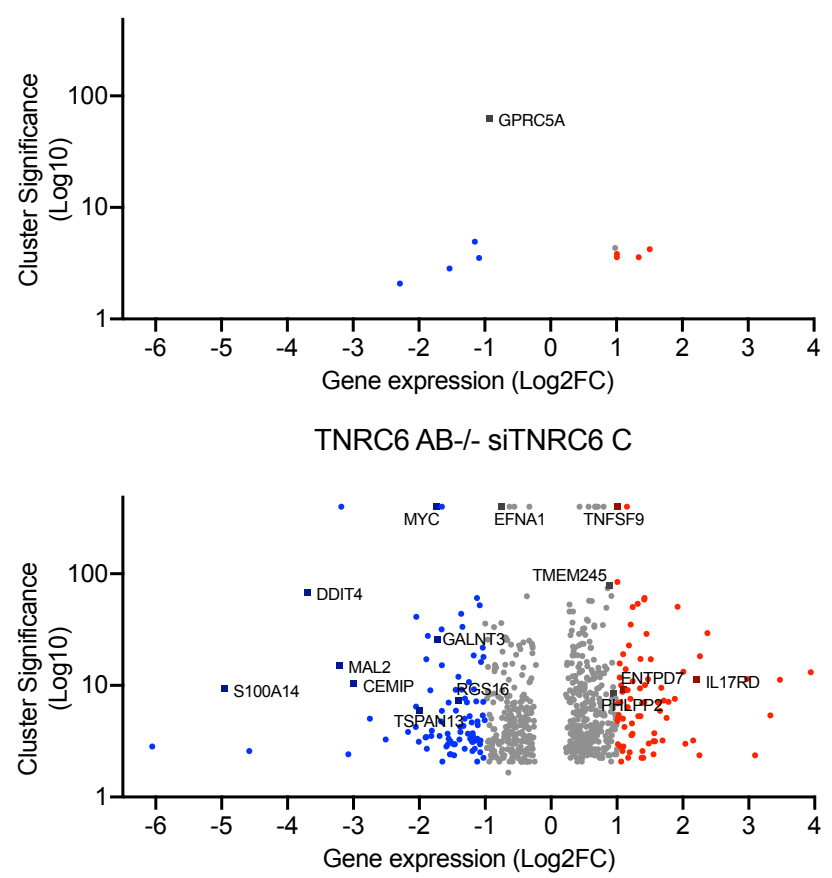
bioRxiv preprint doi: https://doi.org/10.1101/2021.02.09.430449; this version posted February 9, 2021. The copyright holder for this preprint (which was not certified by peer review) is the author/funder, who has granted bioRxiv a license to display the preprint in perpetuity. It is made available under aCC-BY-NC-ND 4.0 International license.

A

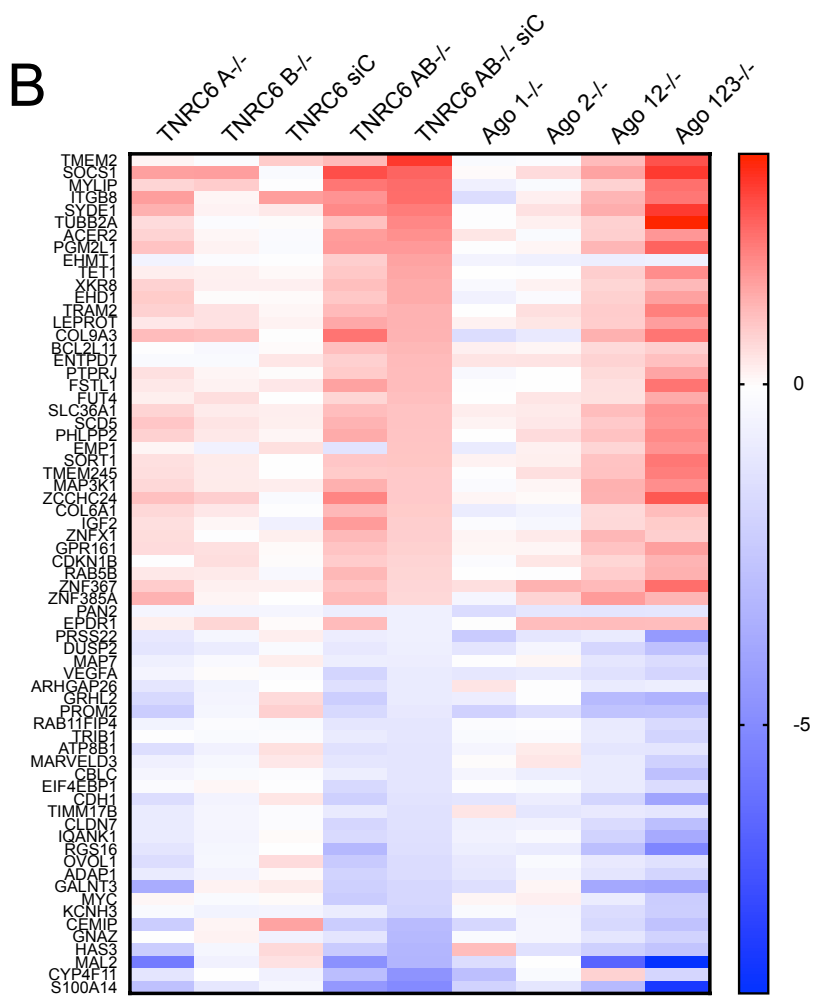

FIGURE 3. Consistent variation for gene expression changes in TNRC6 and AGO knockout cells. $(A)$ Venn diagram showing the overlap of gene expression changes associated with AGO2 binding within 3'-UTRs. (B) Heatmap showing gene expression changes shared by TNRC6 and $A G O$ knockout cell lines. 
A

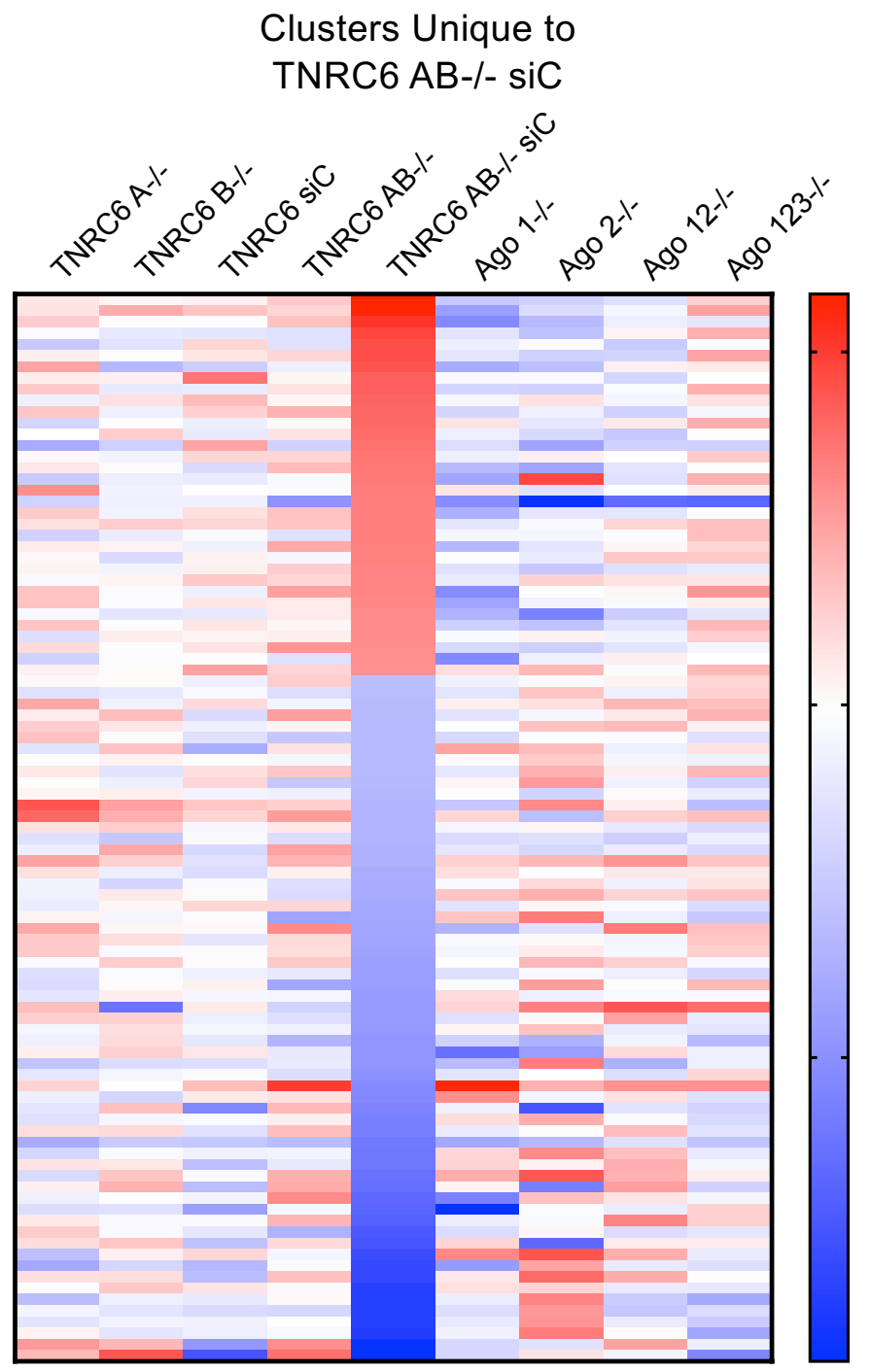

B

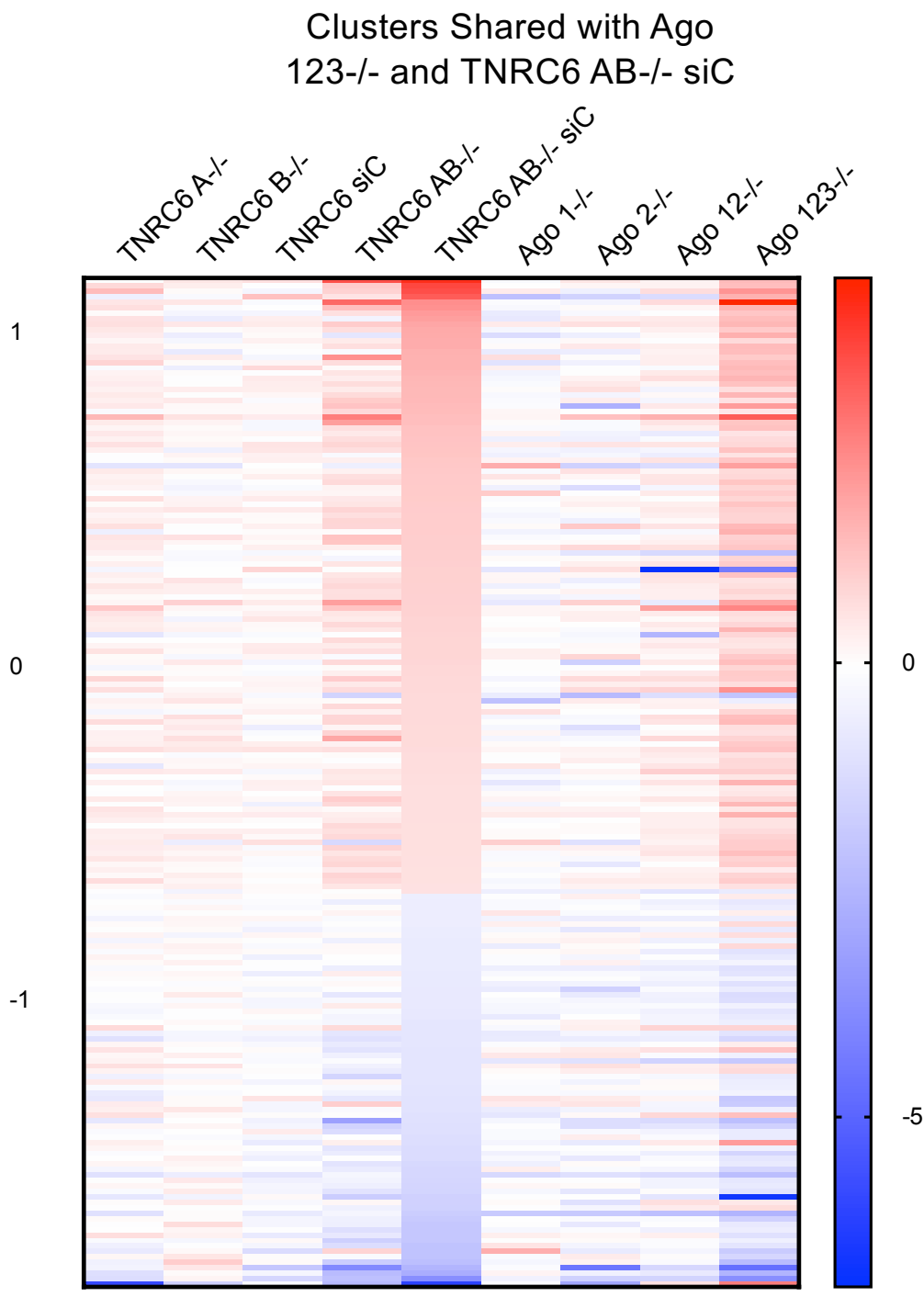

FIGURE 4. Comparison of gene expression in TNRC6 and AGO knockout cells. (A) Heatmap of gene expression changes of 95 genes with AGO2 protein binding clusters that change significantly only in the TNRC6AB-/- knock out/siTNRC6C knockdown cells. (B) Heatmap of gene expression changes of 159 genes with $\mathrm{AGO} 2$ clusters that change significantly in TNRC6 AB-/- siTNRC6C and AGO123-/- cells. 

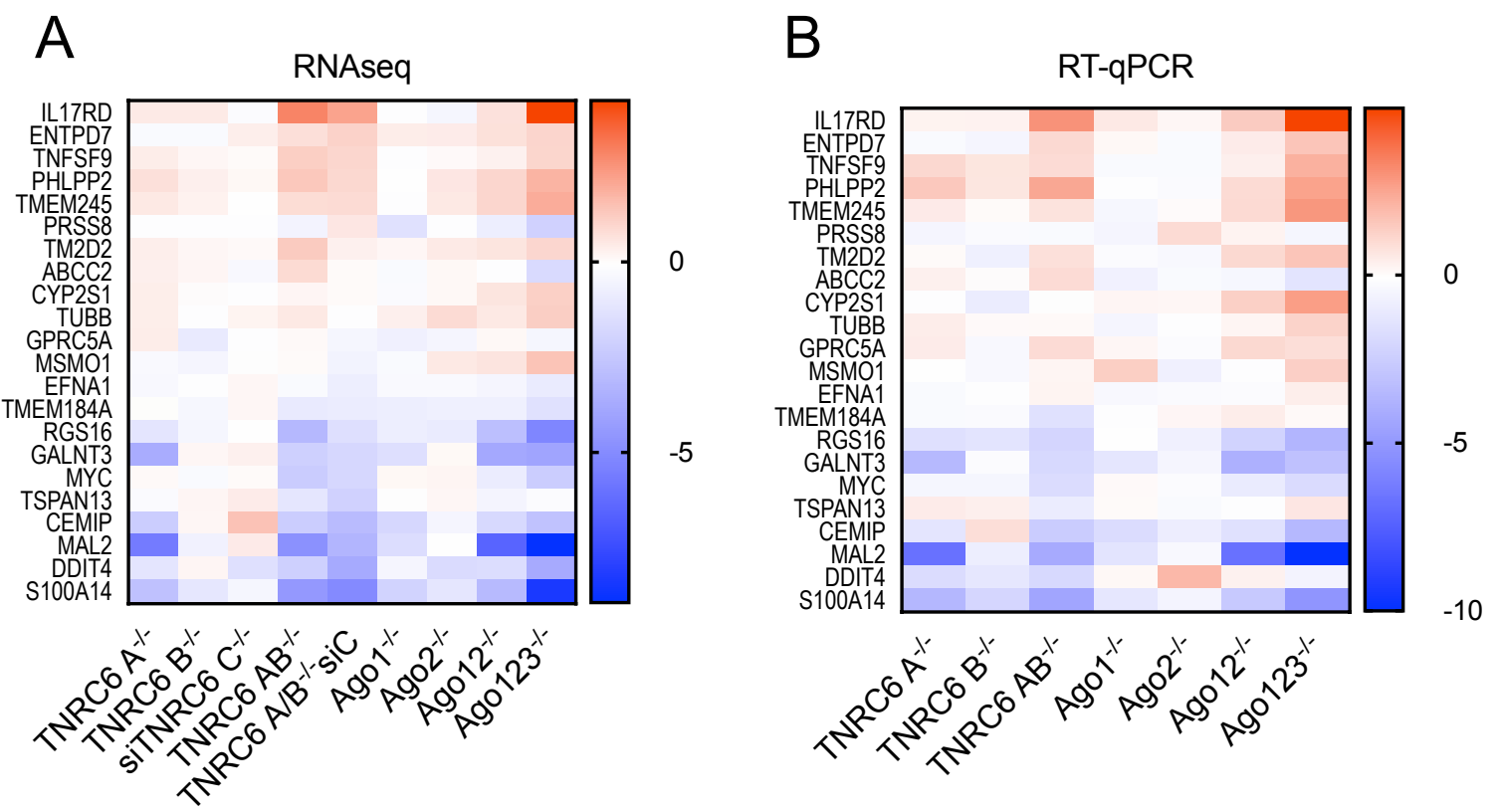

FIGURE 5: Consistent variation of gene expression in cells with highly ranked AGO2 protein binding clusters. (A) Heatmap of gene expression changes from TNRC6 knockout and $A G O$ knockout cell lines from RNA sequencing for 22 cluster genes examined in Chu et al, 2020. (B) Heatmap of gene expression changes from TNRC6 knockout and AGO knockout cell lines from RT-qPCR for 22 cluster genes examined in Chu et al, 2020. 
bioRxiv preprint doi: https://doi.org/10.1101/2021.02.09.430449; this version posted February 9, 2021. The copyright holder for this preprint (which was not certified by peer review) is the author/funder, who has granted bioRxiv a license to display the preprint in perpetuity. It is made available under aCC-BY-NC-ND 4.0 International license.

A

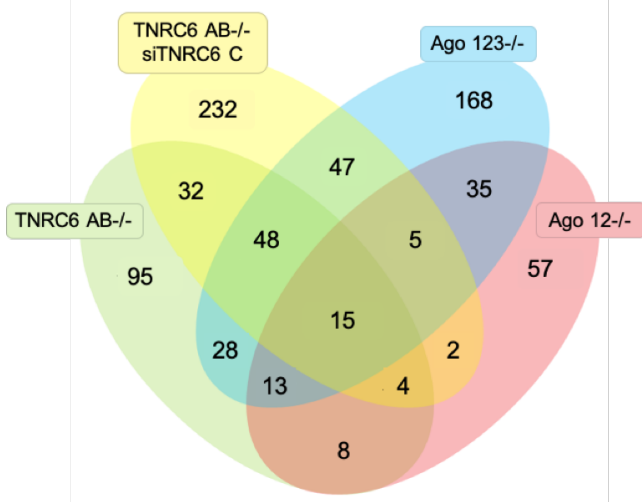

C
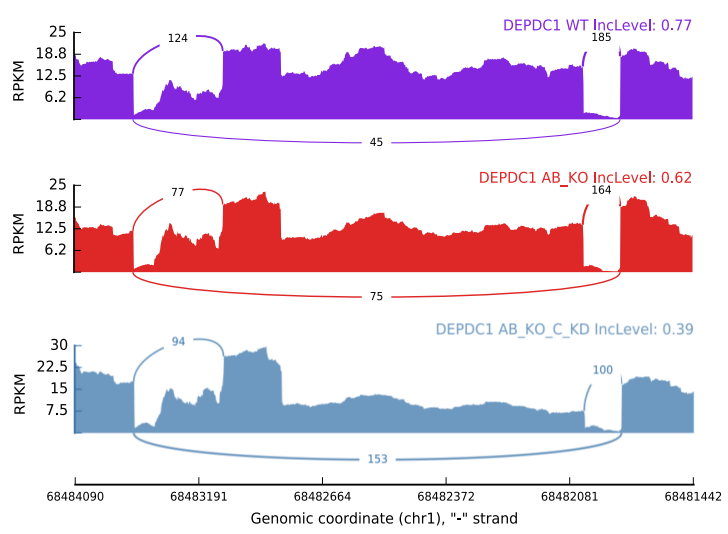

$E$

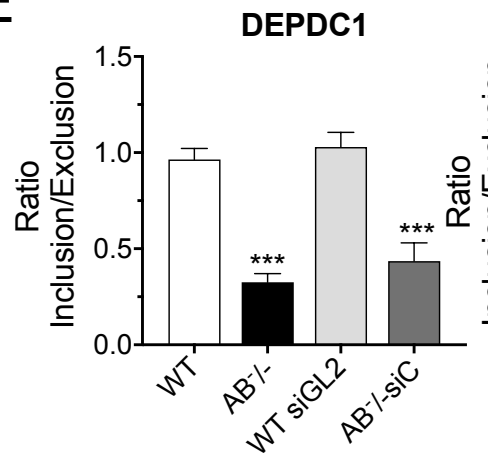

EPB41L2

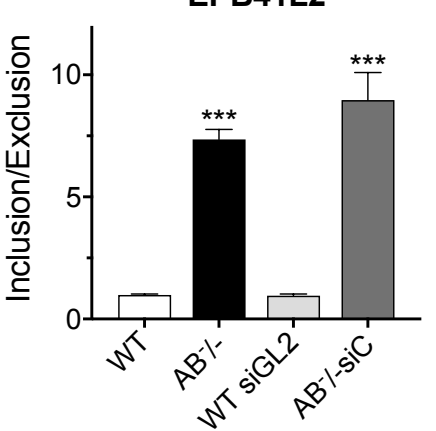

B
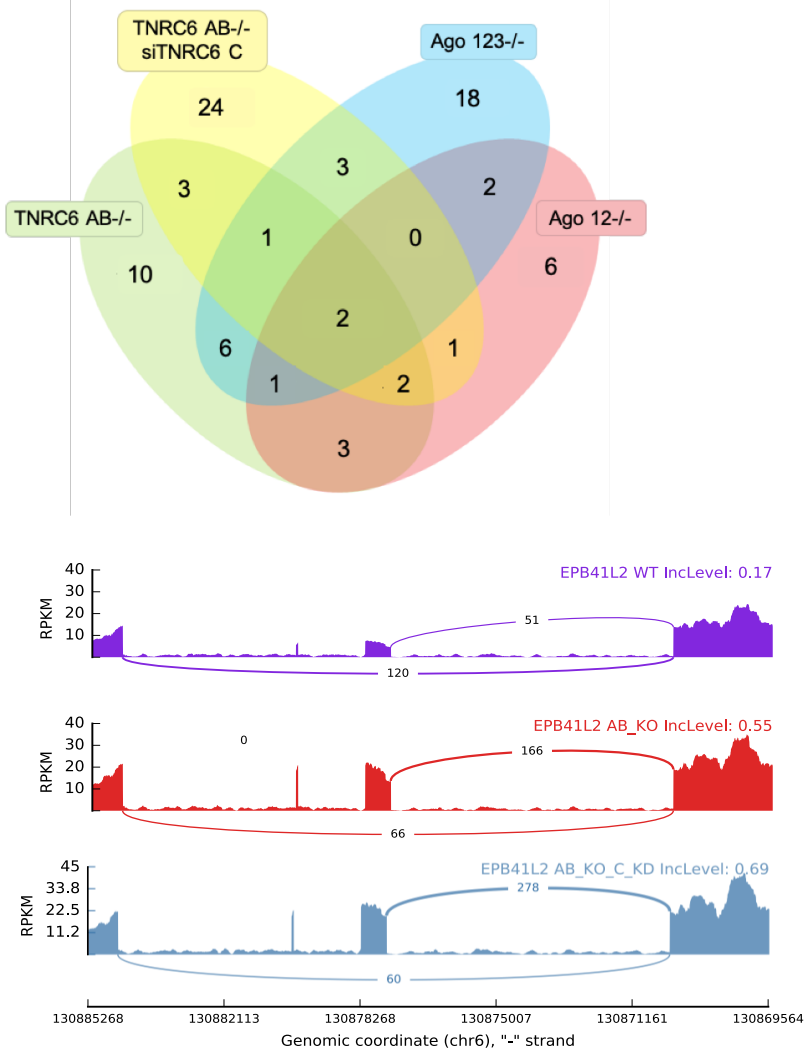

$\mathrm{F}$

EPB41L2

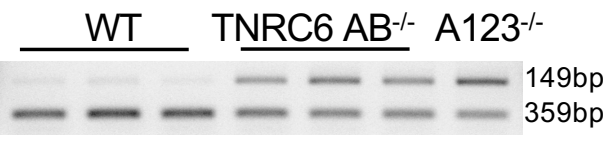

EPB41L2 GEL

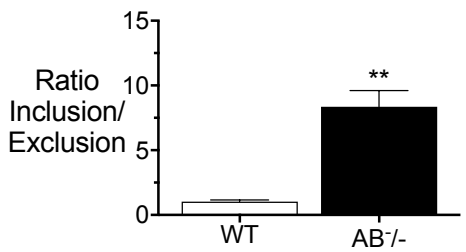

FIGURE 6. Changes in alternative splicing in TNRC6 knockout cell lines. $(A)$ Venn diagram of skipped exon splicing events. $(B)$ Venn diagram of skipped exon splicing events located near AGO2 binding clusters. $(C+D)$ sashimi plots for genes $D E P D C 1$ and EPB41L2 that overlap between TNRC6 $A B-/-$ and $T N R C 6 A B-/-$ siC RNAseq datasets in (B). (E) qPCR validation of skipped exon events in TNRC6 A/B knockout and TNRC6 A/BKO/siC cells. Error bars represent standard deviation (SD). ${ }^{*} \mathrm{P}$ $<0.05 ;{ }^{* *} \mathrm{P}<0.01 ;{ }^{* * *} \mathrm{P}<0.001$ compared with control cell by two tailed $t$-test. (F) Semiquantitative PCR validation of skipped exon events in TNRC6 A/B KO cells and quantitation of the gel. 
A

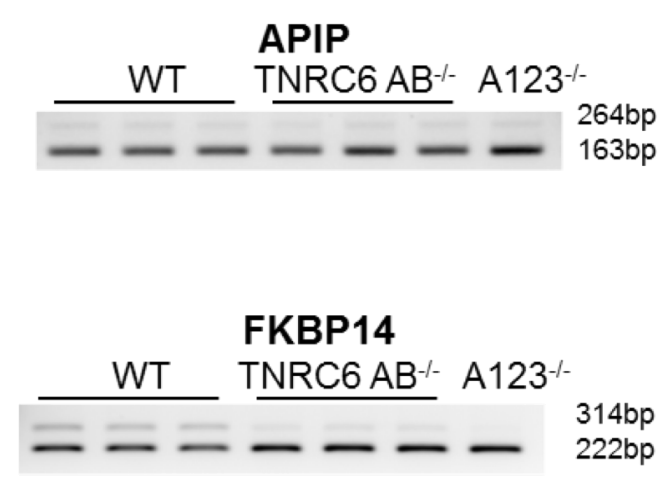

KIF21A

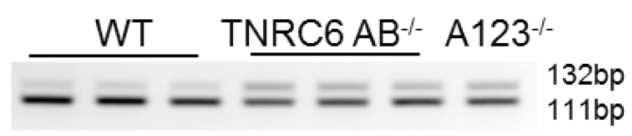

PHLDB1

WT TNRC6 $\mathrm{AB}^{-/-} \mathrm{A} 123^{-/-}$

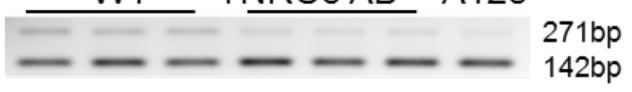

PPIP5K2

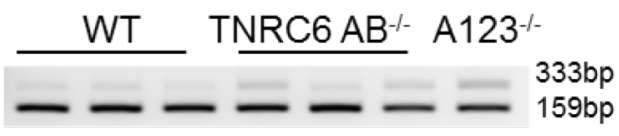

RUBCN

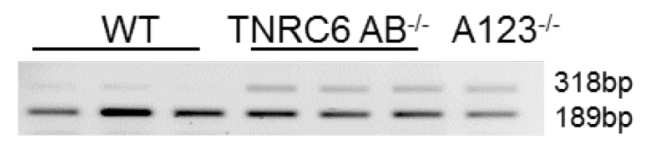

TBC1D5

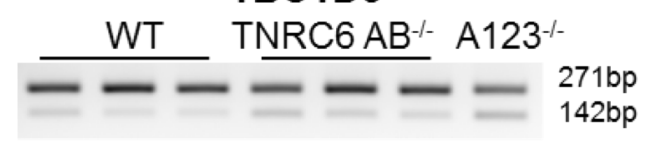

B
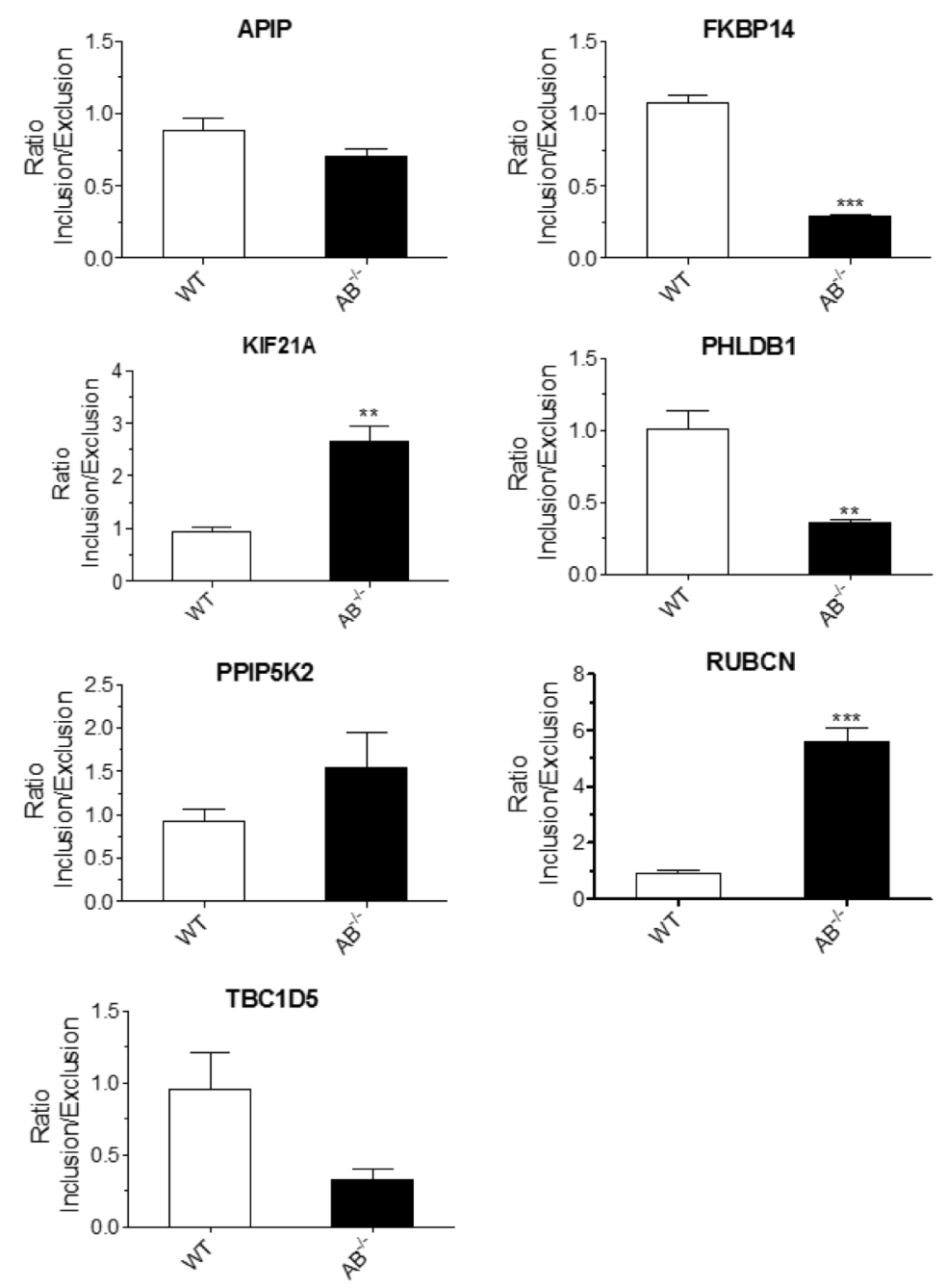

C
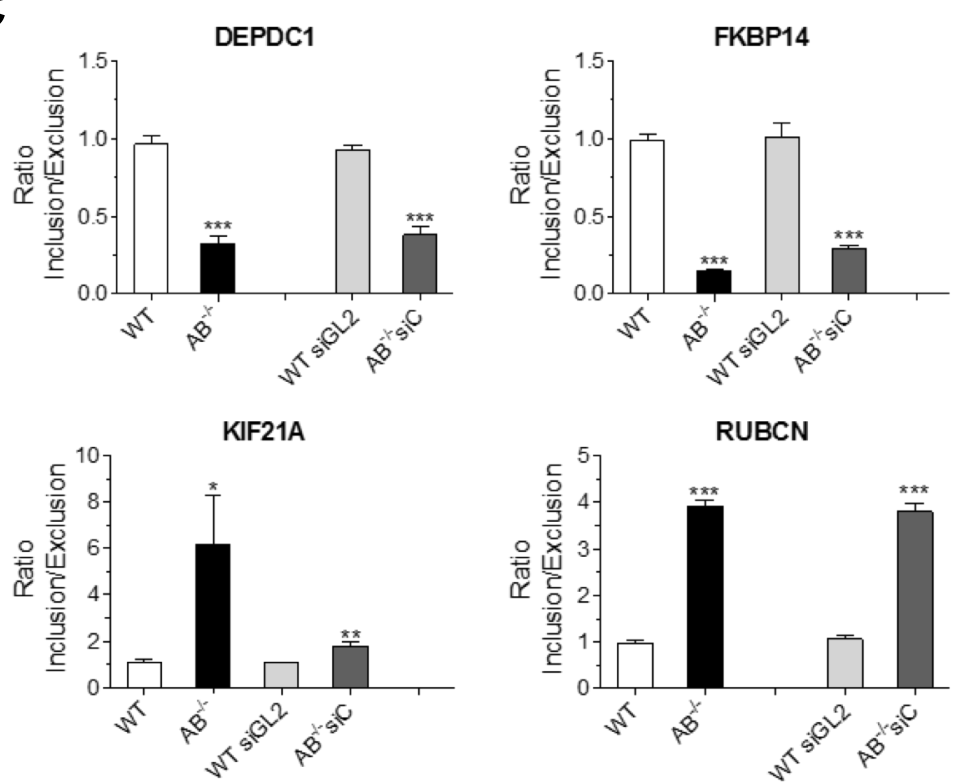

FIGURE 7. Validating the effect of TNRC6 knockouts on alternative splicing. $(A)$ Semiquantitative PCR validation of skipped exon events in TNRC6 A/B knockout cells. (B) Quantitation of data shown in in part (A). (C) QPCR validation of skipped exon events in TNRC6 $A / B$ knockout and TNRC6 A/B knockout/siCTNRC6 knockdown cells. Error bars represent standard deviation (SD). ${ }^{*} P<0.05 ;{ }^{* *} \mathrm{P}<$ $0.01 ;{ }^{* *} \mathrm{P}<0.001$ compared with control cell by two tailed $t$-test. 